\title{
Management of a Second-Trimester Abdominal Pregnancy: A Case Report and Review of the Literature
}

\author{
Abdallah El Farouqi ${ }^{1}$, Essaid Iraki ${ }^{2}$, Anas Boumezzough ${ }^{1}$ \\ ${ }^{1}$ Department of Obstetrics and Gynecology, Agadir Faculty of Medicine and Pharmacy, University Hospital Center, Agadir, \\ Morocco \\ ${ }^{2}$ Surgeon, Regional Hospital Center, Agadir, Morocco \\ Email: elfarouqi.fmpa@gmail.com
}

How to cite this paper: El Farouqi, A., Iraki, E. and Boumezzough, A. (2022) Management of a Second-Trimester Abdominal Pregnancy: A Case Report and Review of the Literature. Open Journal of Obstetrics and Gynecology, 12, 33-42.

https://doi.org/10.4236/ojog.2022.121004

Received: November 30, 2021

Accepted: January 14, 2022

Published: January 17, 2022

Copyright $\odot 2022$ by author(s) and Scientific Research Publishing Inc. This work is licensed under the Creative Commons Attribution International License (CC BY 4.0).

http://creativecommons.org/licenses/by/4.0/

\begin{abstract}
Introduction: The abdominal pregnancy is a rare pathology that can threaten the vital prognosis of the mother. The positive diagnosis is difficult to establish. It is most often made in an acute context, leading to a high fetomaternal morbidity and mortality. Our objective is to recall the diagnostic approach and optimal management of this condition. Case report: We present the case of an abdominal pregnancy at 18 weeks of amenorrhea with partial placental abruption in a 26-year-old patient who presented with abdominal pain in emergency obstetrical department of university hospital center of Agadir. The ultrasound revealed the presence of an evolving abdominal pregnancy. The MRI allowed precisely the localization of the placenta and its relationship with the surrounding organs. A laparotomy revealed the insertion of the placenta on the right adnexa. The right adnexectomy allowed removal of the placenta without incident. Conclusion: Abdominal pregnancy is difficult to diagnose. It is essential to be well informed about the clinical and ultrasonographic semiology of this pregnancy, in order to avoid operative surprises and to ensure the appropriate treatment.
\end{abstract}

\section{Keywords}

Abdominal Pregnancy, Ectopic Pregnancy, Advanced Ectopic Pregnancy

\section{Introduction}

Abdominal pregnancy is a very rare form of ectopic pregnancy, which develops in the peritoneal cavity [1]. The incidence is estimated at 1/10,000, which represents approximately $1 \%$ of all ectopic pregnancies [2] [3]. The potential implantation 
sites include the uterine serosa, omentum, pelvic wall, broad ligament, posterior cul-de-sac, abdominal organs (spleen, bowel, liver), pelvic vessels, and diaphragm [4] [5].

Maternal morbidity and mortality rates are high, largely due to hemorrhage from placental abruption.

The management of abdominal pregnancies depends on gestational age and the site of placental insertion.

We describe the case of an abdominal pregnancy discovered at 18 weeks of amenorrhea and successfully treated by laparotomy in emergency obstetrical department of university hospital center of Agadir.

Our objective is to recall the diagnostic approach and optimal management of this condition.

\section{Case Report}

A 26-year-old woman, primigravida nulliparous, was referred to our unit at 18 weeks of gestation. No contraception was used in the past and no particular personal history was founded in anamnesis.

The patient was presented with the abdominal pain that began abruptly without associated vaginal bleeding. She had undergone an ultrasound, which concluded that she had an evolving intrauterine pregnancy with a pelvic mass.

On physical examination, the patient was apyretic; her hemodynamic status was stable with a heart rate of $81 \mathrm{bpm}$, blood pressure of $110 / 80$, temperature of $37.1^{\circ} \mathrm{C}$. Her abdomen was distended and tender. The cervix is closed.

An abdominal ultrasound on admission showed an evolving monofetal abdominal pregnancy consistent with gestational age, a normal empty uterus, and a fluid effusion in the Douglas cul-de-sac. The placenta was posterior, but its margins were not well visualized (Figure 1).

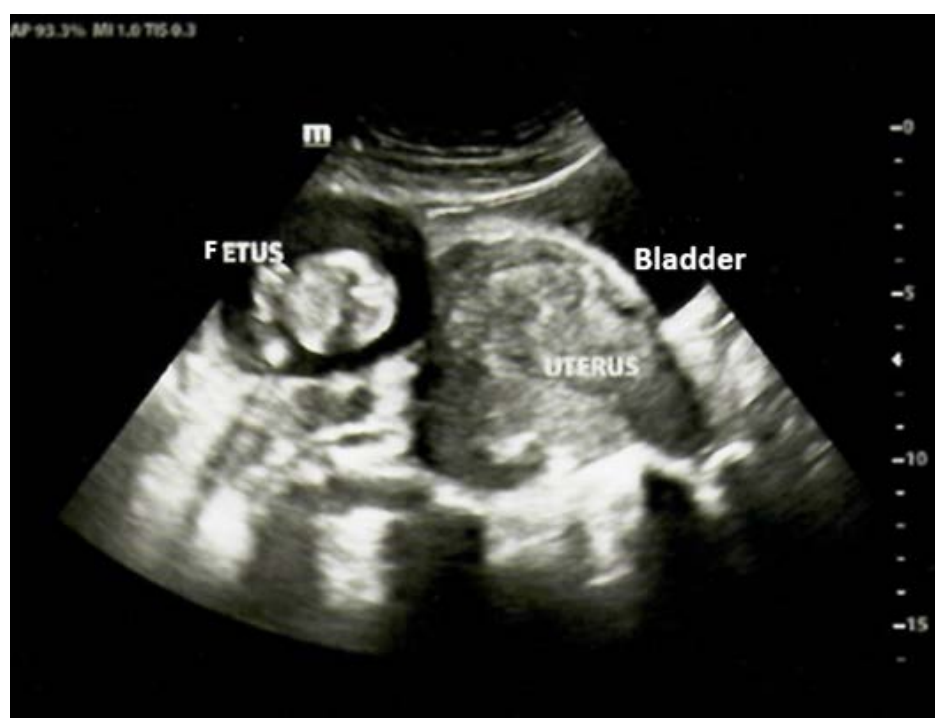

Figure 1. Abdominal ultrasound - Abdominal pregnancy with empty uterus and poorly visualized posterior placenta. 
The MRI showed an intraperitoneal gestational sac located in the left flank. The placenta was located posterolateral to the gestational sac, with insertion on the posterior peritoneum and on the left uterine horn. There was no evidence of other organ involvement (Figure 2).

The patient benefited from a peripheral venous route; laboratory parameters were hemoglobin concentration $9 \mathrm{~g} / \mathrm{dl}$ and hematocrit $30 \%$, total white blood cells of $9000 / \mathrm{mm}^{3}$ and normal platelet count. Blood group and $\mathrm{Rh}$ was $\mathrm{O}$ positive. Blood urea, serum electrolytes and coagulation profiles were within normal limits.

A laparotomy with midline vertical incision was performed and showed:

- An oval fetal sac $(26 \times 20 \mathrm{~cm})$ implanted directly into the abdominal cavity with an uterus of normal volume, lateralized to the right, the right adnexa well individualized and macroscopically normal, the left tube is normal, hemoperitoneum estimated at $800 \mathrm{ml}$.

- The placenta is connected to the left ovary, behind the tube, by a $2 \mathrm{~cm}$ long vascular formation; the left ovarian artery was one of the main feeding vessels of the placenta. The rest of the sac adheres loosely by veils to the abdominal wall and omentum.
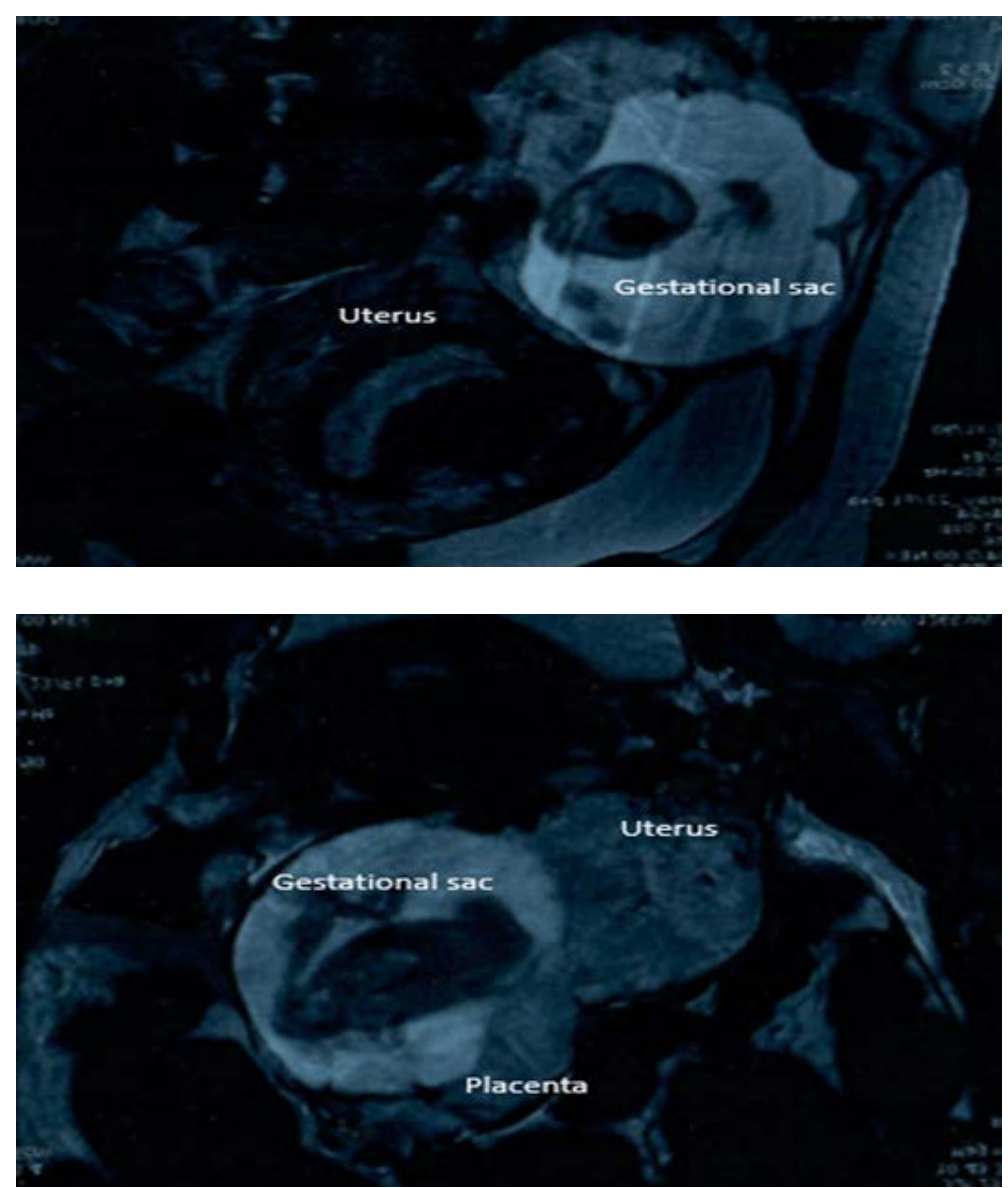

Figure 2. Pelvic MRI - Intraperitoneal gestational sac, ectopic in the left flank. Placenta posterolateral to the gestational sac. 
These adhesions are easily cleaved by hand. The fetus, which was superior to the uterus, was first removed through a large incision in the amniotic sac, away from the placenta. This one was partially detached from the posterior peritoneum, but still attached to the left adnexa and ovarian vessels. The absence of invasion of the large vessels or the intestinal tract is noted.

The gestational sac was then extracted, the placenta was removed after a left adnexectomy and the hemoperitoneum was aspirated.

The bowel and others intraabdominal organs were examined, no damage was detected.

Post-operative recovery was uneventful and the patient was discharged on 7th post-operative day and the follow-up of the patient was without anomaly; on the 4 months follow up visit she's healthy.

\section{Discussion}

Abdominal pregnancy is a very rare entity [6]. The main complications are bleeding, infections, anemia, coagulopathy, pulmonary embolism and gastrointestinal fistulas [7].

The main risk factors are ectopic pregnancy, tubal lesions, pelvic inflammatory disease, endometriosis, assisted reproductive techniques and multiparity [8] [9] [10].

There are 2 types of abdominal pregnancies related to physiopathological mechanism: [11] [12].

- Secondary abdominal pregnancies, the most frequent, result from tubo-abdominal abortion or rupture of a tubal pregnancy.

- Primary pregnancies are due to the implantation of the fertilized ovum in the peritoneal cavity due to delayed ovulation.

Our case can be classified as a primary abdominal pregnancy because the uterine body and the tubes are intact.

Clinical signs of the abdominal pregnancy are not specific. The diagnosis is not always easy. 50\% of diagnoses are incorrect [1] [13] [14] and only $45 \%$ are diagnosed preoperatively [6]. Advanced abdominal pregnancies have been discovered after failed induction of labor [15].

Several symptoms help guide the diagnosis [3] [6] [16] [17] [18]. Abdominal pain is the most common symptom, concomitant with fetal movements with or without vaginal bleeding. The gastrointestinal symptoms are seen in $70 \%$ of cases.

Abnormal fetal presentation, easily palpable fetal parts, and a displaced cervix (40\%) [2] [6] [14] [18] should raise a suspicion.

Acute form due to intraabdominal bleeding with several abdominal pain and shock has also been reported.

Imaging is used to confirm the diagnosis, to locate the placenta and to study its vascularization [9] [19] [20].

Ultrasound is the primary means of diagnosis. It is limited by many factors, 
including maternal obesity, meteorism, and the operator's experience.

The ultrasound shows the presence of a fetus outside the uterus, the absence of the uterine wall between the bladder and fetus, ectopic location of the placenta, oligohydramnios, fetus adjacent to the mother's abdominal contents, abnormal fetal presentation, and the absence of amniotic fluid between the fetus and placenta [21] [22].

The diagnosis in our case was obtained by the ultrasonography which showed suggestive signs, such as uterine vacuity and gestational sac not surrounded by the myometrium, located above the uterus with an abdominal effusion most probably related to hemoperitoneum.

Magnetic Resonance Imaging (MRI) is a very useful tool for identifying the placental implantation site, its feeder vessels, and its relationship to the large vessels, intestine, or other vital structures [23] [24].

In our patient, MRI was used to locate the placental insertion and its relationship to the surrounding organs.

The fetal prognosis is poor, with a mortality rate of $80 \%$ to $90 \%$, related to defective vascularization of the placenta, hypotrophy, and fetal malformations [1] [14] [18] [21]. at $90 \%$ of surviving fetuses have severe congenital malformations secondary to oligohydramnios and vascular disturbances [25] [26] [27] [28].

The maternal prognosis depends on the delay in diagnosis and the attitude taken towards the placenta, and maternal mortality is high. The rate varies in the literature from $0.5 \%$ to $20 \%$ [1] [6] [14] [16] [18] [28] [29].

Maternal morbidity and mortality are secondary to severe hemorrhage, occlusive syndrome, fistulas or disseminated intravascular coagulation [14] [16].

The optimal treatment of abdominal pregnancy is not defined. There are many therapeutic options depending on intraoperative exploration and gestational age.

Surgical option is the mainstay of treatment. The laparotomy should be performed through a midline incision [14]. It is advisable to make the incision in the amniotic sac as far away from the placental insertion as possible and large enough to remove the fetus without trauma [30].

The dilemma is how to deal with the placenta, which depends on the site of its insertion. The ideal treatment of the placenta is debated. Removal of the placenta remains the rule whenever possible; if it is possible to ligate the feeder vessels, if the diagnosis is early in pregnancy, or in cases of fetal death of more than four weeks [14], the removal of the placenta is associated with the best postoperative outcome, with fewer complications [6] [14] [16] and fewer reoperations [31] [32]. The procedure consists of the initial ligation of the placental vessels before its removal [18].

In a review of 225 cases reported in the literature, the average blood loss was $1450 \mathrm{ml}$ (range $50-700 \mathrm{ml}$ ), so it is necessary to perform preoperative arterial embolization with the presence of a multidisciplinary surgical team [33] [34].

Sometimes the removal of the placenta is not possible because of massive vas- 
cular invasion or insertion on a noble organ [5] [35]. In this case, any attempt at extirpation exposes the placenta to massive hemorrhage that may damage the organ site of insertion [5] [35] [36] [37]. In this case, it is permissible to leave the placenta in place by cutting the cord as short as possible and to institute close monitoring to identify potential complications [38] [39].

Some authors advise against leaving the placenta in situ because this attitude is responsible for a high rate of complications (50\%) [6] [27]: secondary hemorrhage, coagulopathy, intestinal obstruction, infection, peritonitis, prolonged hospital stay, and the need for a second surgical intervention [6] [16] [27]. In the case of fetal death, some recommend delayed extraction to allow for vessel atrophy [40]. This decision is controversial because of the high risk of coagulopathy and infection [6] [27] [41]. In case of profuse hemorrhage, in addition to resuscitative measures, it would be useful to perform embolization associated with manual pressure, sutures, or epiploic grafting. In this case, it is necessary to preserve the vascularity of the surrounding organs [6].

In our case, the placental insertion was only on the left adnexa and on the posterior peritoneum away from the large vessels, which allowed complete removal after left adnexectomy.

If the placenta is left in place, other measures may be combined to facilitate placental resorption, including methotrexate treatment or embolization [6] [14] [16] [42]. Physical examination, Ultrasound, inflammatory changes and beta hcg levels can guide in monitoring the process of placental resorption.

Human chorionic beta-gonadotropin levels can regress in 4 months, with an average of about 50 days [27] [43]. The placental resorption can sometimes take up to years [27].

Methotrexate can be used in the postoperative period to accelerate placental resorption. However, its use is controversial, with some believing it to be useful in accelerating placental resorption, while others do not recommend its use, because of the rapid degradation of the placenta, which is responsible for the accumulation of necrotic tissue with a major risk of sepsis [27] [44]. Other authors suggest that methotrexate could be used at lower doses to prevent rapid destruction of the placenta and accumulation of excess necrotic tissue [45].

Vessel embolization can be performed before surgery [44] [46] and after surgery in case of postoperative hemorrhage [46].

There is a role for conservative management in select cases [6] [18] [40], diagnosed above 24 weeks, in order to achieve viability this is only possible; in the absence of fetal malformation, in the absence of maternal or fetal decompensation, when placental implantation low in the abdomen away from the liver or spleen, adequate amniotic fluid and in centers where there are facilities for close inpatient monitoring [30] [47]. The laparotomy can be scheduled at 34 weeks of amenorrhea if there are no complications.

\section{Conclusions}

We present here a rare case of abdominal pregnancy diagnosed at 18 weeks of 
amenorrhea. The clinical and radiological evaluation allowed us to define the placental implantation preoperatively. Fetal extraction and complete removal of the placenta was possible without incident.

Abdominal pregnancy is often difficult to diagnose with a high risk of fetomaternal morbidity and mortality. Late diagnosis and the possibility of noble organ involvement increase complications. However, the early diagnosis offers a better prognosis. Any obstetrician must think about it when faced with evocative clinical and ultrasound semiology and ensure optimal management.

\section{Ethical Approval}

Ethical clearance is obtained from the patient herself by written and informed consent as well from Obstetrics \& Gynecology Department.

\section{Conflicts of Interest}

The authors declare no conflicts of interest regarding the publication of this paper.

\section{References}

[1] Atrash, H.K., Friede, A. and Hogue, C.J. (1987) Abdominal Pregnancy in the United States: Frequency and Maternal Mortality. Obstetrics \& Gynecology, 69, 333-337.

[2] Fisch, B., Peled, Y., Kaplan, B., Zehavi, S. and Neri, A. (1996) Abdominal Pregnancy Following in Vitro Fertilization in a Patient with Previous Bilateral Salpingectomy. Obstetrics \& Gynecology, 88, 642-643. https://doi.org/10.1016/0029-7844(96)00213-X

[3] Onan, M.A., Turp, A.B., Saltik, A., Akyurek, N., Taskiran, C. and Himmetoglu, O. (2005) Primary Omental Pregnancy: Case Report. Human Reproduction, 20, 807-809. https://doi.org/10.1093/humrep/deh683

[4] Shippey, S.H., Bhoola, S.M., Royek, A.B. and Long, M.E. (2007) Diagnosis and Management of Hepatic Ectopic Pregnancy. Obstetrics \& Gynecology, 109, 544-546. https://doi.org/10.1097/01.AOG.0000247293.32523.c3

[5] Mbura, J.S. and Mgaya, H.N. (1986) Advanced Abdominal Pregnancy in Muhimbili Medical Centre, Tanzania. International Journal of Gynecology \& Obstetrics, 24, 169-176. https://doi.org/10.1016/0020-7292(86)90094-9

[6] Nkusu Nunyalulendho, D. and Einterz, E.M. (2008) Advanced Abdominal Pregnancy: Case Report and Review of 163 Cases Reported since 1946. Rural and Remote Health, 8, Article No. 1087. https://doi.org/10.22605/RRH1087

[7] Riethmuller, D., Courtois, L., Maillet, R. and Schaal, J.P. (2003) Ectopic Pregnancy Management: Cervical and Abdominal Pregnancies. Journal de gynécologie, obstétrique et biologie de la reproduction, 32, S101-S108. [Article in French]

[8] Goh, T.H. and Rahman, S.A. (1980) Primary Peritoneal Pregnancy Implanted on the Uterine Fundus. Australian and New Zealand Journal of Obstetrics and Gynaecology, 20, 240-241. https://doi.org/10.1111/j.1479-828X.1980.tb00775.x

[9] Delabrousse, E., Site, O., Le Mouel, A., Riethmuller, D. and Kastler, B. (1999) Intrahepatic Pregnancy: Sonography and CT Findings. American Journal of Roentgenology, 173, 1377-1378. https://doi.org/10.2214/ajr.173.5.10541123

[10] Norenberg, D.D., Gundersen, J.H., Janis, J.F. and Gundersen, A.L. (1997) Early 
Pregnancy on the Diaphragm with Endometriosis. Obstetrics \& Gynecology, 49, 620-622.

[11] Bouzid, F., Mounal, G., Aboudagher, F. and Racinet, C. (1992) Early Diagnosis of Pregnancy in a Rudimentary Horn. Journal de gynécologie, obstétrique et biologie de la reproduction, 21, 263-264. [Article in French]

[12] Sfar, E, Kaabar, H., Marrakechi, O., Zouari, F., Chelli, H., Kharouf, M., et al. (1993) Abdominal Pregnancy; Rare Anatomo-Clinical Entity: À propos de 4 cas entre 1981 et 1990. Revue française de gynécologie et do obstétrique, 88, 261-265.

[13] Martin Jr., J.N., Sessums, J.K., Martin, R.W., Pryor, J.A. and Morrison, J.C. (1988) Abdominal Pregnancy: Current Concepts of Management. Obstetrics \& Gynecology, 71, 549-557.

[14] Rahman, M.S., Al-Suleiman, S.A., Rahman, J. and Al-Sibai, M.H. (1982) Advanced Abdominal Pregnancy. Observations in 10 Cases. Obstetrics \& Gynecology, 59, 366-372.

[15] Hersh, E.G, Bolognese, R.J. and Corson, S.L. (1977) Undiagnosed Abdominal Pregnancy with Inadvertent Prostaglandin Administration. American Journal of Obstetrics and Gynecology, 129, 110-111. https://doi.org/10.1016/0002-9378(77)90829-8

[16] Molinaro, T.A. and Barnhart, K.T. (2007) Ectopic Pregnancies in Unusual Locations Seminars in Reproductive Medicine. Seminars in Reproductive Medicine, 25, 123-130. https://doi.org/10.1055/s-2007-970051

[17] Tsudo, T., Harada, T., Yoshioka, H. and Terakawa, N. (1997) Laparoscopic Management of Early Primary Abdominal Pregnancy. Obstetrics \& Gynecology, 90, 687-688. https://doi.org/10.1016/S0029-7844(97)00127-0

[18] Dahab, A.A., Aburass, R., Shawkat, W., Babgi, R, Essa, O. and Mujallid, R.H. (2011) Full-Term Extrauterine Abdominal Pregnancy: A Case Report. Journal of Medical Case Reports, 5, Article No. 531. https://doi.org/10.1186/1752-1947-5-531

[19] Malian, V. and Lee, J.H. (2001) MR Imaging and MR Angiography of an Abdominal Pregnancy with Placental Infarction. American Journal of Roentgenology, 177, 1305-1306. https://doi.org/10.2214/ajr.177.6.1771305

[20] Otoide, V.O. and Ojobo, S. (2002) Ultrasound Diagnosed Abdominal Pregnancy at 34 Weeks' Gestation. Journal of Obstetrics and Gynaecology, 22, 319-320. https://doi.org/10.1080/01443610252971230

[21] Allibone, G.W., Fagan, C.J. and Porter, S.C. (1981) The Sonographic Features of Intra-Abdominal Pregnancy. Journal of Clinical Ultrasound, 9, 383-387. https://doi.org/10.1002/jcu.1870090706

[22] Angtuaco, T.L., Shah, H.R., Neal, M.R. and Quirk, J.G. (1994) Ultrasound Evaluation of Abdominal Pregnancy. Critical Reviews in Diagnostic Imaging, 35, 1-59.

[23] Lockhat, F., Corr, P., Ramphal, S. and Moodley, J. (2006) The Value of Magnetic Resonance Imaging in the Diagnosis and Management of Extra-Uterine Abdominal Pregnancy. Clinical Radiology, 61, 264-269. https://doi.org/10.1016/j.crad.2005.10.013

[24] Renfroe, S., Dajani, N.K., Pandey, T. and Magann, E.F. (2013) Role of Serial MRI Assessment in the Management of an Abdominal Pregnancy. Case Reports, 2013, Article ID: bcr2013200495. https://doi.org/10.1136/bcr-2013-200495

[25] Agarwal, N. and Odejinmi, F. (2014) Early Abdominal Ectopic Pregnancy: Challenges, Update and Review of Current Management. The Obstetrician \& Gynaecologist, 16, 193-198. https://doi.org/10.1111/tog.12109

[26] Gidiri, M.F. and Kanyenze, M. (2015) Advanced Abdominal Ectopic Pregnancy: Lessons from Three Cases from Zimbabwe and a Literature Appraisal of Diagnostic 
and Management Challenges. Women's Health, 11, 275-279. https://doi.org/10.2217/WHE.15.3

[27] Kun, K.Y., Wong, P.Y., Ho, M.W., Tai, C.M. and Ng, T.K. (2000) Abdominal Pregnancy Presenting as a Missed Abortion at 16 Weeks' Gestation. Hong Kong Medical Journal, 6, 425-427.

[28] Galluzzo, R.N, Cardoso, G.M. and Leite Santos, M. (n.d.) Abdominal Pregnancy. https://thefetus.net/content/abdominal-pregnancy-2/

[29] Hailu, F.A., Yihunie, G.T., Essa, A.A. and Tsega, W.K. (2017) Advanced Abdominal Pregnancy, with Live Fetus and Severe Preeclampsia, Case Report. BMC Pregnancy and Childbirth, 17, Article Number: 243. https://doi.org/10.1186/s12884-017-1437-y

[30] Martin Jr., J.N. and McCaul, J.F. (1990) Emergent Management of Abdominal Pregnancy. Clinical Obstetrics and Gynecology, 33, 438-447. https://doi.org/10.1097/00003081-199009000-00008

[31] Hreshchyshyn, M.M., Bogen, B. and Loughran, C.H. (1961) What Is the Actual Present-Day Management of the Placenta in Late Abdominal Pregnancy? Analysis of 101 Cases. American Journal of Obstetrics and Gynecolog, 81, 302-317.

[32] Ayinde, O.A., Aimakhu, C.O., Adeyanju, O.A. and Omigbodun, A.O. (2005) Abdominal Pregnancy at the University College Hospital, Ibadan: A Ten-Year Review. African Journal of Reproductive Health, 9, 123-127. https://doi.org/10.2307/3583166

[33] Worley, K.C., Hnat, M.D. and Cunningham, F.G. (2008) Advanced Extrauterine Pregnancy: Diagnostic and Therapeutic Challenges. American Journal of Obstetrics and Gynecology, 198, 297.E1-297.E7. https://doi.org/10.1016/j.ajog.2007.09.044

[34] Tucker, K., Bhardwaj, N.R., Clark, E., Kaler, M.K., Atueyi, F. and Allen, R. (2017) Delayed Diagnosis and Management of Second Trimester Abdominal Pregnancy. Case Reports, 2017, Article ID: bcr-2017-221433. https://doi.org/10.1136/bcr-2017-221433

[35] Yildizhan, R., Kolusari, A., Adali, F., Adali, E., Kurdoglu, M., Ozgokce, C., et al. (2009) Primary Abdominal Ectopic Pregnancy: A Case Report. Cases Journal, 2, Article No. 8485. https://doi.org/10.4076/1757-1626-2-8485

[36] White, R.G. (1989) Advanced Abdominal Pregnancy-A Review of 23 Cases. Irish Journal of Medical Science, 158, 77-78. https://doi.org/10.1007/BF02942151

[37] Oliver, R., Malik, M., Coker, A. and Morris, J. (2007) Management of Extra-Tubal and Rare Ectopic Pregnancies: Case Series and Review of Current Literature. Archives of Gynecology and Obstetrics, 276, 125-131.

https://doi.org/10.1007/s00404-006-0311-3

[38] Roberts, R.V., Dickinson, J.E., Leung, Y. and Charles, A.K. (2005) Advanced Abdominal Pregnancy: Still an Occurrence in Modern Medicine. Australian and New Zealand Journal of Obstetrics and Gynaecology, 45, 518-521. https://doi.org/10.1111/j.1479-828X.2005.00489.x

[39] Masukume, G., Sengurayi, E., Muchara, A., Mucheni, E., Ndebele, W. and Ngwenya, S. (2013) Full-Term Abdominal Extrauterine Pregnancy Complicated by Post-Operative as Cites with Successful Outcome: A Case Report. Journal of Medical Case Reports, 7, Article No. 10. https://doi.org/10.1186/1752-1947-7-10

[40] Varma, R., Mascarenhas, L. and James, D. (2003) Successful Outcome of Advanced Abdominal Pregnancy with Exclusive Omental Insertion. Ultrasound in Obstetrics \& Gynecology, 21, 192-194. https://doi.org/10.1002/uog.25

[41] Kitade, M., Takeuchi, H., Kikuchi, I., Shimanuki, H, Kumakiri, J. and Kinoshita, K. 
(2005) A Case of Simultaneous Tubal-Splenic Pregnancy after Assisted Reproductive Technology. Fertility and Sterility, 83, 1042.E19-1042.E21. https://doi.org/10.1016/j.fertnstert.2004.10.047

[42] Cardosi, R.J., Nackley, A.C., Londono, J. and Hoffman, M.S. (2002) Embolization for Advanced Abdominal Pregnancy with a Retained Placenta. A Case Report. Journal of Reproductive Medicine, 47, 861-863.

[43] Pisarska, M.D., Casson, P.R., Moise Jr., K.J., Di Maio, D.J., Buster, J.E. and Carson, S.A. (1998) Heterotopic Abdominal Pregnancy Treated at Laparoscopy. Fertility and Sterility, 70, 159-160. https://doi.org/10.1016/S0015-0282(98)00104-6

[44] Rahaman, J., Berkowitz, R., Mitty, H., Gaddipati, S., Brown, B. and Nezhat, F. (2004) Minimally Invasive Management of an Advanced Abdominal Pregnancy. Obstetrics \& Gynecology, 103, 1064-1068.

https://doi.org/10.1097/01.AOG.0000127946.14387.48

[45] Da Silva, B.B., de Araujo, E.P., Cronemberger, J.N., dos Santos, A.R. and Lopes-Costa, P.V. (2008) Primary Twin Omental Pregnancy: Report of a Rare Case and Literature Review. Fertility and Sterility, 90, 2006.E13-2006.E15.

https://doi.org/10.1016/j.fertnstert.2008.03.038

[46] Kivikoski, A.I., Martin, C., Weyman, P., Picus, D. and Giudice, L. (1988) Angiographic Arterial Embolization to Control Hemorrhage in Abdominal Pregnancy: A Case Report. Obstetrics \& Gynecology, 71, 456-459.

[47] Ang, L.P., Tan, A.C. and Yeo, S.H. (2000) Abdominal Pregnancy: A Case Report and Literature Review. Singapore Medical Journal, 41, 454-457. 